\title{
La prevención de las enfermedades virales en la comunidad
}

DR. ANTONIO BANFI ***.

Cuando se plantea el papel que desempeña la investigación epidemiológica en los programas de prevención de diversas enfermedades virales tales como Poliomielitis, Viruela, Sarampión y otras, es necesario concordar en que los elementos del estudio y la metodología a emplear difieren en diversos aspectos. Son distintos no sólo en cuanto a las enfermedades mismas, sino también en lo que se refiere a la situación epidemiológica propia de cada país y al estado de control de las distintas enfermedades en sus comunidades.

En Chile, la investigación epidemiológica de las enfermedades virales ha sido de gran valor en la prevención de ellas y en la actualidad contempla diversos enfoques que hacen más completa su proyección. Los estudios epidemiológicos deben estar basados, para obtener conclusiones valederas, en el conocimiento preciso de importantes datos acerca de cada enfermedad: morbilidad, mortalidad, notificación obligatoria, investigación de laboratorio en los casos individuales o epidémicos; estudios serológicos comunitarios con el objeto de determinar el grado de susceptibilidad de la población; información clara y precisa acerca del empleo de las vacunas; datos demográficos actualizados $\mathrm{y}$ aspectos socioeconómicos $\mathrm{y}$ ambientales.

Tal como en diversos países del continente americano, en Chile los programas de prevención de las enfermedades de etiología viral han estado dirigidos, fundamentalmente, hacia las afecciones que potencial o bien prácticamente son las principales causas de morbilidad y mortalidad como es el caso de la poliomielitis y el sarampión. Otro grupo de enfermedades, que no presentan un problema de la importancia epidemiológica de los

- Hospital Luis Calvo Mackenna.

** Unidad de Microbiologia, Area Oriente. Universidad de Chile. cuadros antes señalados, han sido estudiados serológicamente y esto ha permitido establecer que no es necesario mantener un programa de prevención obligatorio.

\section{RUBEOLA}

Esta enfermedad, que se encuentra en la situación recién descrita, es una afección generalmente benigna pero, que encierra un peligro cierto de daño embrionario si es adquirida por una madre durante el primer trimestre de embarazo (1). El principal objetivo de la vacunación contra la rubeola es la prevención del riesgo connatal y debería estar dirigida, principalmente, a las mujeres susceptibles en edad de gestación.

Con el objeto de investigar el estado inmunitario de la población femenina, la $\mathrm{O}$ M S patrocinó en 1968 un estudio colaborativo sero-epidemiológico en diversos países del Caribe y Sudamérica. En Chile (2), tal como en otros países, la mayoría de las mujeres estudiadas presentaban anticuerpos para rubeola en tasas suficientes, tabla 1. Posteriormente en 1973 y en 1974, se evaluó nuevamente en mujeres en edad de gestación (3) y en embarazadas (4), el estado inmunitario y se comprobó que las tasas de anticuerpos para rubeola eran de 80 y $77 \%$ respectivamente.

Actualmente la rubeola no es una enfermedad de notificación obligatoria en nuestro país y consecuentemente, con los datos obtenidos en 1968, 1973 y 1974 , no se mantiene un programa de vacunación, puesto que la infección natural mantiene a la población femenina en estado inmune. Será necesario revisar periódicamente el estado inmunitario de nuestra población femenina frente a la rubeola, realizando estudios semejantes al señalado. 
T A B L A 1

Es otra enfermedad que en la actualidad no representa problema desde el punto de vista epidemiológico. La experiencia mundial en la erradicación de la viruela ha demostrado que la investigación epidemiológica con el empleo adecuado de los datos es el hecho más importante del programa de prevención (5).

En Chile, la enfermedad ha sido erradicada desde hace años (6) y se mantiene un programa de vacunación con la primera dosis a los 12-14 meses de edad y luego revacunaciones cada 5 años.

Debido al éxito que ha tenido la prevención de la viruela a nivel mundial, se hace necesario revisar el criterio para mantener un programa de vacunación. En la actualidad se ha pensado en discontinuar la vacunación antivariólica en aquellos países en que ha desaparecido la viruela, que no limitan con países con endemia de la enfermedad y que cuentan con servicios de salud aptos para tomar las medidas de control en caso de reaparición de la viruela (7).

\section{INFLUENZA}

Uno de los aspectos negativos en la historia del control de las enfermedades virales es el que representa la influenza; este es, probablemente, uno de los más importantes problemas virales considerando su trascendencia económica. La variación antigénica que experimentan los virus influenza $A$, que son los principales agentes de las epidemias, dificulta extremadamente la prevención de la enfermedad y consecuentemente la preparación de vacunas contra la influenza que sean realmente efectivas es un problema que aún no ha sido resuelto en forma satisfactoria.

En nuestro país se realiza anualmente, desde 1970 , un censo serológico representativo destinado a investigar la inmunidad comunitaria frente a virus influenza A y B $(8,9,10)$. Desde 1968 hasta 1972 , los brotes de influenza $A$ se debieron a virus semejantes al A/Hong Kong/8/68 $\left(\mathrm{H}_{3}\right.$ $\mathrm{N}_{2}$ ). En 1972 y 1973 los virus $\mathrm{A}$ aislados en nuestro país, fueron semejantes a la variante $\mathrm{A} / \mathrm{En}$ gland/42/72 $\left(\mathrm{H}_{3} \mathrm{~N}_{2}\right)$, es decir experimentaron una variación antigénica respecto del virus A prototipo de 1968. Nuevamente, en 1974, los virus influenza $\mathrm{A}$ que presentaron en Chile tuvieron un cambio en su estructura antigénica (11) siendo esta similar a la del prototipo A/Port Chalmers/ $73\left(\mathrm{H}_{3} \mathrm{~N}_{2}\right)$ el cual es el último agente que ha sufrido un cambio estructural sustancial, respecto del virus $\mathrm{A} / \mathrm{Hong} \mathrm{Kong} / 8 / 68$. Estas sucesivas variaciones de los virus Influenza explican la dificultad enorme que existe para poder controlar tan importante enfermedad.
ESTUDIO SEROEPIDEMIOLOGICO DE RUBEOLA. SANTIAGO, CHILE 1968

\begin{tabular}{rccr}
\hline $\begin{array}{l}\text { Edad } \\
\text { años }\end{array}$ & Positivo & $\begin{array}{c}\text { Número de casos } \\
\text { Total }\end{array}$ & $\%$ \\
\hline $5-9$ & 37 & 38 & 97 \\
$10-14$ & 24 & 24 & 100 \\
$15-19$ & 42 & 47 & 89 \\
$20-24$ & 81 & 83 & 98 \\
$25-34$ & 86 & 89 & 97 \\
\hline
\end{tabular}

Estos estudios han permitido conocer los grupos etarios susceptibles y así programar vacunaciones previas a los períodos de actividad de influtenza. Sin embargo, la magnitud de los brotes de la enfermedad no es posible predecirla y de este modo subsiste el problema de control de esta afección.

\section{POLIOMIELITIS - SARAMPION}

Para Chile, estas dos enfermedades han significado un serio problema de morbilidad y mortalidad hasta comienzos de los años 60 . Posteriormente se ha ido logrando un progresivo y cada vez más amplio control de tales afecciones y la importancia que ha tenido la vacunación en la reducción significativa de la morbilidad y mortalidad es innegable.

En nuestro país, la vacuna antipoliomielítica oral tipo Sabin trivalente se ha empleado regularmente desde 1962 y desde ese año hasta la fecha las cifras de morbilidad y mortalidad se redujeron ostensiblemente (12). Hasta 1971 la vacunación antipoliomielítica en nuestro país comprendía el siguiente esquema: primera dosis de vacuna Sabin trivalente a los 3 meses de edad; segunda dosis a los 5 meses de edad; tercera a los 18 meses y posteriormente revacunaciones cada dos años hasta la edad escolar.

En 1969 se decidió evaluar este programa realizando una encuesta serológica durante los meses de Marzo a Junio época de menor prevalencia de los virus polio, y se pudo comprobar en forma significativa que la seroconvención positiva, no alcanzaba a más de un $70 \%$ para cualquiera de los tres tipos de virus polio (13). Paralelamente se comprobó que la población infantil no vacunada comprendida entre 1 y 4 años, era altamente susceptible, puesto que la infección natural alcanzaba a un $32 \%$ para polio 1 y $41 \%$ y $50 \%$ para virus polio 2 y 3 respectivamente. Más tarde en el verano de 1969-70, se presentó un brote de la 
SUSCEPTIBILIDAD E INMUNIDAD AL VIRUS POLIO 1 AL NACER Y A LOS 3 MESES DE EDAD EN RECIEN NACIDOS CONTROLES Y VACUNADOS CON VACUNA SABIN TIPO 1. SANTIAGO - CHILE, 1971

\begin{tabular}{|c|c|c|c|c|c|c|c|c|c|}
\hline \multirow[t]{3}{*}{ Total } & \multicolumn{3}{|c|}{ Recién Nacidos } & & \multicolumn{4}{|c|}{3 Meses de Edad } & \multirow[b]{3}{*}{$\%$} \\
\hline & \multicolumn{2}{|c|}{ Susceptibles } & \multicolumn{2}{|c|}{ Inmunes } & \multicolumn{2}{|c|}{ Susceptibles } & \multirow{2}{*}{-} & \multirow{2}{*}{$\begin{array}{c}\text { Inmunes } \\
N^{\circ}\end{array}$} & \\
\hline & $N^{\rho}$ & $\%$ & $N^{o}$ & $\%$ & $N^{9}$ & $\%$ & & & \\
\hline Controles & & & & & & & & & \\
\hline 52 & 4 & 7,6 & 48 & 92,3 & 30 & 57,7 & & 22 & 42,3 \\
\hline Vacunados & & & & & & & & & \\
\hline 110 & 12 & 10,9 & 98 & 89,1 & 15 & 13.6 & & 95 & 86,4 \\
\hline
\end{tabular}

enfermedad debido a virus polio 1 y afectó preferentemente a los niños entre 1 y 4 años (14). Frente a la realidad de estos hechos, se realizó un programa de vacunación masiva y se buscó una modificación del esquema de vacunación que mejorara sustancialmente la protección de los niños frente al virus polio 1 .

En 1971 se realizó un estudio destinado a ver la respuesta serológica del recién nacido vacunado con vacuna Sabin monovalente polio 1 (15). Los resultados de este trabajo han sido muy satisfactorios, (tabla 2) y con la vacuna se logra mantener un alto porcentaje de niños inmunes a los 3 meses de edad. A partir de esta experiencia, se ha incorporado en forma permanente la vacunación del recién nacido con vacuna Sabin polio 1 .

En 1971 y en 1973 en la ciudad de Santiago se estudiaron serológicamente a niños de diferentes edades (16-17). En el grupo etario de 0-3 años, la seropositividad frente a virus polio 1 después de haber recibido vacunaciones incluyendo la del período de recién nacido subió a un $97 \%$ en 1971 y en 1973 alcanzó a un 91\%. Estos resultados demuestran la eficacia de la vacunación antipoliomielítica actualmente vigente en nuestro país.

Sólo el enfoque epidemiológico integral del problema que significa la poliomielitis permitirá que pueda cumplirse con el objetivo de erradicar la enfermedad.

Tal como en el caso de la poliomielitis, en Chile se ha logrado un progreso claro en el control del sarampion y desde 1965 en que la vacunación alcanzó una mayor cobertura la morbilidad y la mortalidad disminuyeron paulatinamente. Sin embargo, el problema está lejos de su resolución y factores propios de un país en vías de desarrollo mantienen la problemática.

Desde hace dos años se está desarrollando una tesis de postgrado (18) sobre la inmunidad frente al sarampión en los primeros 8 meses de vida. Es posible que el aporte de esta tesis permita modificar nuestro actual programa de control del sarampión.
Si bien es cierto, que actualmente se dispone de adecuadas vacunas para un grupo importante de enfermedades virales y que algunas de ellas han sido erradicadas o bien disminuído significativamente, hay otras afecciones para las cuales aun no se logra un adecuado y eficiente control.

Es un deber fundamental de una comunidad, insistir en la creación o perfeccionamiento de servicios de salud eficientes y suficientes que empleen en la forma más adecuada todos los métodos de la investigación epidemiológica con los recursos más amplios posibles. Sólo teniendo en cuenta estos aspectos básicos podrá haber un real progreso en el control de las enfermedades virales en la comunidad.

\section{RESUMEN}

Se presenta la prevención de las enfermedades virales más importantes en nuestra comunidad.

Se señala la necesidad de contar con elementos apropiados para la completa investigación epidemiológica.

\section{SUMMARY}

In this paper it is presented the control of the most important viral diseases in Chilean community.

It is mandatory for a community to have appropiate services for complete epidemiological investigation.

\section{REFERENCIAS}

1.-Banfi, A. Aspectos de las virosis connatales. Neonatología I: 22-25, 1971.

2.-Pearson, E., et al. "WHO Colaborative Study on the Sero-Epidemiology of Rubella in Caribbian and South American Populations". 1968.

3.-Vergara, M. I. y Morales, H. Estudio serológico de rubeola en áreas rurales 1973. Dpto. Virus Instituto Bact. Chile y Sección Epidemiología SNS. Trabajo no publicado. 
4.-Vergara, M. I.; Foxley, R.; Iglesias, J.; Corbalán, G. Rubeola y Embarazo. Rev. Soc. Chil. Obst. y Ginecol., 1974 en prensa.

5.- Henderson, D. A. WHO Working Paper, 34, 1968.

6.-Repetto, G. Vacunación Antivariólica y Viruela. Antecedentes históricos y estado actual. Rev. Chil. Ped. 45: 78-87 1974.

7.-Raska, K. WHO Seminar. Montevideo, 1968.

8.-Vicente, M.; Falaha, F.; Riqueros, S. Estudio de Anticuerpos de Influenza A y B en la población del Area Poniente de Santiago en 1970. Bol. Inst. Bact. Chil. 12: 19-25, 1970.

9.-Vicente, M.; Falaha, F.; Riqueros, S. Estudio de Anticuerpos de Influenza A y B en población del Area Poniente de Santiago. Bol. Inst. Bact. Chil. 13: 33-37, 1971.

10.-Vicente, M.; Falaha, F.; Vicent, P.; Cánepa, 1.; Riqueros, S.; Salas, L. Vigilancia Serológica de Influenza A y B en el Area Poniente de Santiago 1972 a 1974) Rev. Med. Chil. 102: 847-849, 1974.

11.-Vicente, M. Comunicación personal.
12.- Servicio Nacional de Salud. Enfermedades de Notificación Obligatoria, 1971.

13.-Vicente, M.; Borgoño, J. M.; Greiber, R.; Carrillo, B., Concha, F. Experiencia con distintas dosis de vacuna antipoliomielítica Sabin Trivalente en niños. Bol. Inst. Bact. Chil. 13: 73-78, 1971.

14.-Vergara, M. I.; Vicente, M.; Banfi, A. Poliomielitis en Chile. Estudio de Laboratorio $\square$ parte, Brote de Polio. Agosto 69-Agosto 70. Rev. Chil. Pediat. 42: 239-243, 1971.

15.-Banfi, A.; Vergara, M. I.; Avendaño, O.; Borgoño, J. M.; Greiber, R.; Solari, G.; Concha, F. Vacunación del recién nacido con Vacuna Antipoliomielítica Oral Sabin tipo 1. Estudio serológico. Rev. Chil. Ped. 6: Nov-Dic., 1974.

16.-Vergara, M. I. Poliomielitis: Estudio serológico. Evaluación vacunación Sabin 1971. Trabajo no publicado.

17.-Vergara, M. I. Poliomielitis. Estudio serológico. Evaluación vacunación Sabin 1973. Trabajo no publicado.

18.- Cofré, J. Estudio de la inmunidad antisarampión en los primeros 8 meses de vida. Tesis post-grado, en desarrollo. U. de Chile. Sede Oriente. 